\title{
Diabetic glomerulosclerosis can be the pathogenesis of refractory diabetic macular edema
}

This article was published in the following Dove Press journal:

Clinical Ophthalmology

25 May 2015

Number of times this article has been viewed

\section{Eman Saeed Al Kahtani \\ King Khaled Eye Specialist Hospital, Riyadh, Saudi Arabia}

Background: Kidney failure provoked by glomerulosclerosis leads to fluid filtration deficits and other disorders of kidney function. Refractory diabetic macular edema (DME) can be another warning sign of glomerulosclerosis in diabetic patients.

Case: A 40-year-old Saudi male presented with macular edema that was refractory to all possible medical and surgical ophthalmic interventions in both eyes. The macular edema significantly improved once the patient began systemic treatment for newly diagnosed diabetic glomerulosclerosis. This case report is presented with optical coherence tomography (OCT) documentation of before and after each medical and surgical intervention.

Observations: Considerable improvement occurred after treatment with a systemic angiotensin-converting enzyme inhibitor and diuretic treatment due to newly diagnosed diabetic glomerulosclerosis.

Conclusion: Refractory DME can be secondary to diabetic glomerulosclerosis. This case indicates the possibility that systemic intervention may be warranted in cases of refractory DME, and the importance of collaboration between ophthalmologists, endocrinologists, and internists in these cases.

Keywords: angiotensin-converting enzyme inhibitor, diuretic, proteinuria

\section{Introduction}

Diabetic macular edema (DME) is the most common cause of vision loss in diabetics. DME is associated with an insidious and painless onset of decreased vision. DME can be either secondary to focal leakage of microaneurysms or due to diffuse edema that occurs from extensive breakdown of the blood-retinal barrier with leakage of both microaneurysms and ischemic retinal capillaries. Loss of vision may range from mild to profound. ${ }^{1}$

Diabetic nephropathy, known as Kimmelstiel-Wilson syndrome or nodular diabetic glomerulosclerosis, is caused by angiopathy of capillaries in the kidney glomeruli of diabetic patients. $^{2}$

Kidney failure provoked by glomerulosclerosis leads to fluid filtration deficits and other disorders of kidney function. ${ }^{2}$ High blood pressure may be the earliest sign of the disease. ${ }^{3}$ Secondary fluid retention in the body plus a reduced plasma oncotic pressure causes edema and swelling of the face, eyes, ankles, feet, legs, and abdomen. Refractory DME can be another warning sign and feature of this disease. ${ }^{4}$

The author reports the case of a young non-insulin-dependent type 2 diabetic who underwent all possible medical and surgical interventions to treat bilateral macular edema without success. The patient was diagnosed with diabetic glomerulosclerosis
Correspondence: Eman Saeed Al Kahtani King Khaled Eye Specialist Hospital, PO Box 7I9I, Riyadh II462, Kingdom of Saudi Arabia

Tel +966 I| 482 I 234 ext 2049 Fax+966 I| 482 I 234 ext 2044 Email ekahtani@kkesh.med.sa 
by a nephrologist and treated with a systemic angiotensinconverting enzyme inhibitor and diuretic medication that resolved the refractory DME.

\section{Case report}

A 40-year-old Saudi male with type 2 non-insulin-dependent diabetes mellitus initially presented in July 2007 to the retina department at King Khaled Eye Specialist Hospital, Riyadh, Saudi Arabia, complaining of floaters and a gradual decrease in vision for months. Diabetes was managed with diet and sitagliptin, an oral hypoglycemic agent (Januvia ${ }^{\circledR}$; Merck and Co, Inc, Whitehouse Station, NJ, USA).

The patient appeared healthy with a history of wellcontrolled blood sugar, no hypertension, and healthy kidneys. The patient had a semi-round face, which was considered normal. Best corrected visual acuity (VA) was 20/60 in the right eye and 20/40 in the left eye; the intraocular pressure was normal with an unremarkable anterior segment examination. Fundus examination showed bilateral high-risk proliferative diabetic retinopathy associated with diabetic maculopathy due to edema secondary to a leaking microaneurysm and capillary dropout (Figure 1A).

The patient underwent bilateral panretinal photocoagulation and intravitreal injection of Avastin ${ }^{\circledR} 1.25 \mathrm{mg} / 0.05 \mathrm{~mL}$ (bevacizumab; Genentech Inc, San Francisco, CA, USA). Two weeks after Avastin injection, the patient underwent focal laser for a leaking microaneurysm and grid laser for capillary dropout. During follow-up visits, the patient received another session of panretinal photocoagulation for active proliferative diabetic retinopathy, additional grid laser treatment for ischemic macular edema, three additional intravitreal Avastin injections bilaterally, and two intravitreal injections of triamcinolone acetonide $4 \mathrm{mg} / 0.1 \mathrm{~mL}$. Despite the aggressive treatment, macular edema and subretinal fluid persisted during all follow-up visits in the following 2.5 years (Figure $1 \mathrm{~B})$.

Pars plana vitrectomy and internal membrane peeling for assumed traction on the macula from a thick hyaloid and to improve the oxygen supply of the macula were performed bilaterally with minimal improvement in VA to 20/50 in the right eye and 20/30 in the left eye (Figure $2 \mathrm{~A}$ and B). Recurrent vs refractory DME was the final diagnosis and the patient was advised to consult a nephrologist to evaluate the status of his kidneys due to unintentional weight gain; swelling of the face, hands, and feet; shortness of breath; and persistent blurred vision.

The nephrologist ordered urinalysis, which indicated heavy proteinuria. Further testing included transcutaneous
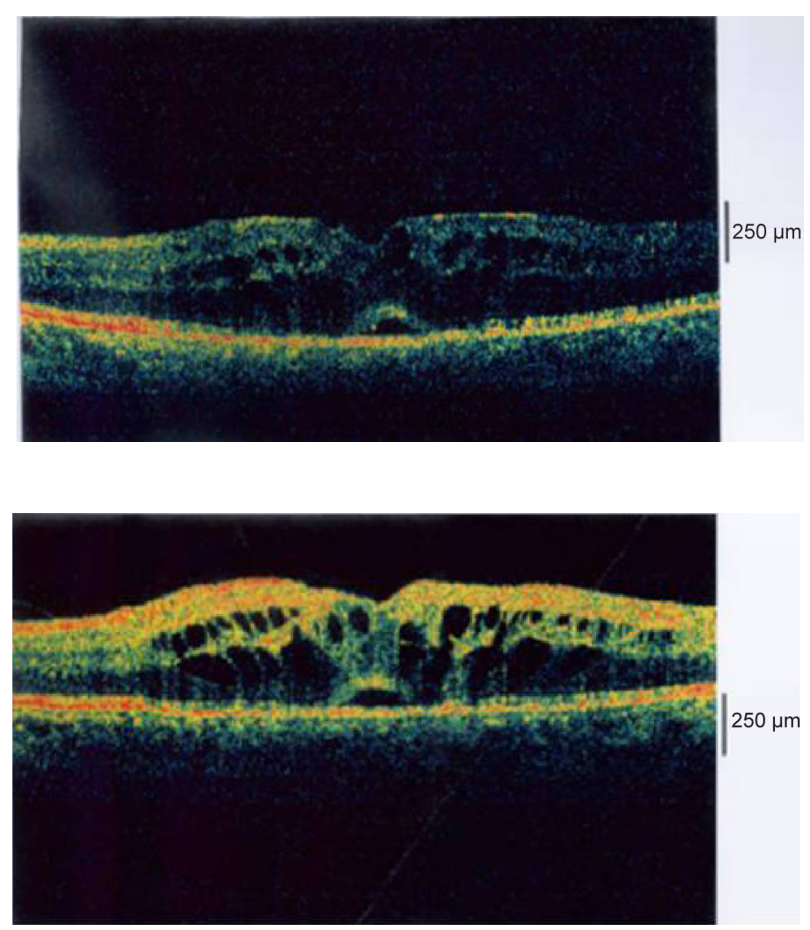

Figure I (A) Optical coherence tomography images of the patient's right and left maculae at the first visit to the King Khaled Eye Specialist Hospital, Riyadh, Saudi Arabia, showing cystic changes and subretinal fluid in both eyes. (B) Optical coherence tomography images of the maculae after multiple treatments consisting of Avastin ${ }^{\circledR}$ and/or triamcinolone acetonide injections, focal and grid laser. Persistent cystic changes and subretinal fluid are present in both maculae. 

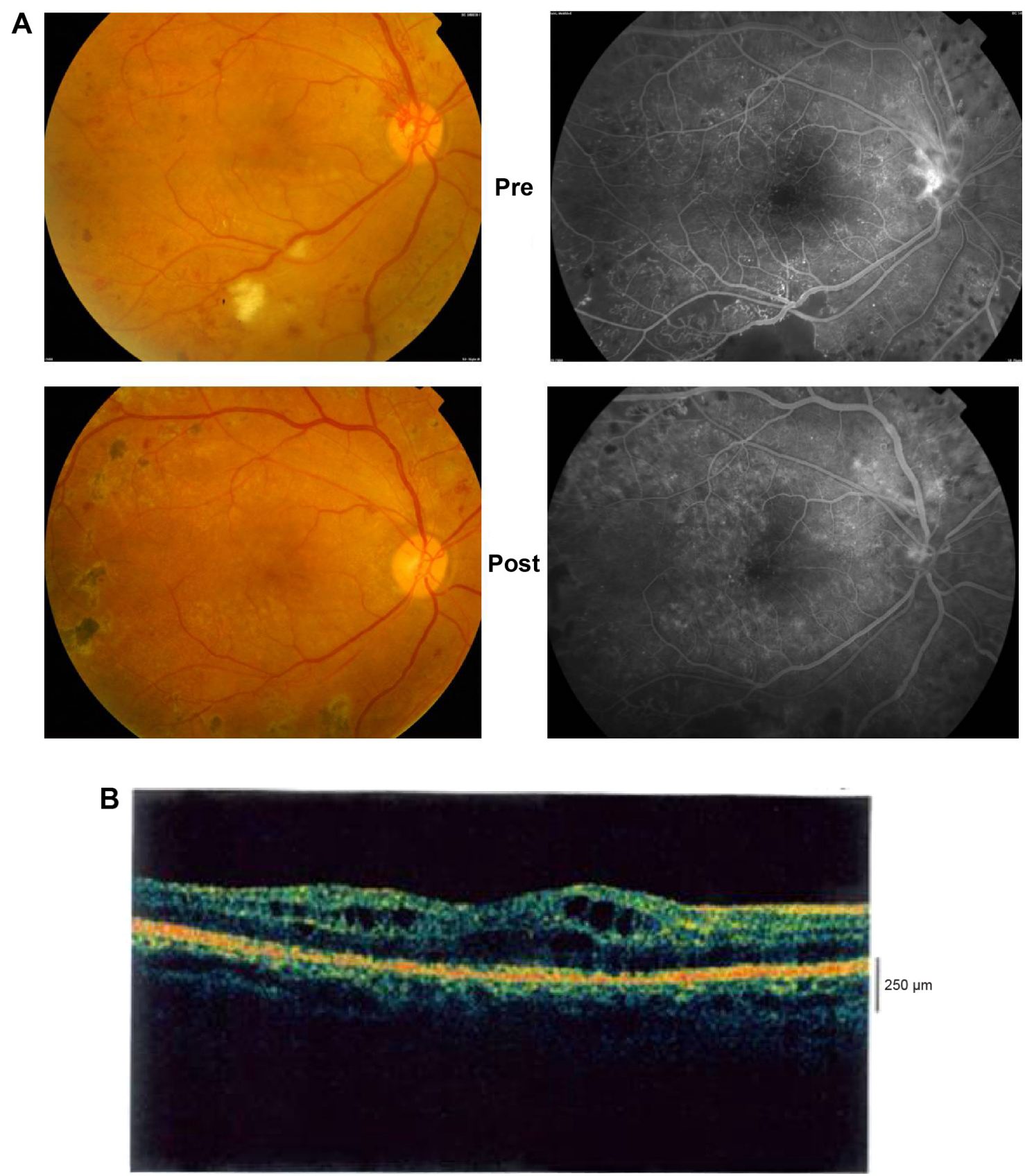

Figure 2 (A) Fluorescein angiographs (left) and photographs (right) of the fundus before and after pars plana vitrectomy and internal membrane peeling, showing improvement in retinal micro- and macro-circulation. (B) Optical coherence tomography image of the macula in bilateral pars plana vitrectomy and internal membrane peeling, showing refractory macular edema.

biopsy of the left kidney, which indicated diabetic glomerulosclerosis. Negative immunohistochemistry and electron microscopy ruled out any other pathology that may have been impairing renal function, such as infection or autoimmune disease.

The nephrologist recommended a salt-restricted diet, diuretic therapy (frusemide $80 \mathrm{mg}$ ), and an angiotensinconverting enzyme inhibitor (valsartan) in addition to the original management protocol. Over 8 weeks, the patient lost
$20 \mathrm{~kg}$ in weight, which was likely to be just water and salt. The symptoms of shortness of breath and peripheral hand and foot swelling regressed markedly with the treatment regimen. Macular edema improved, with a marked reduction in cystic changes and central thickness and the subretinal fluid also disappeared. VA improved to 20/25 in both eyes (Figure 3A).

On follow-up, the patient had finished his prescriptions of frusemide and valsartan and the macular edema was found to have recurred, resulting in decreased VA, to 20/70 in the right 

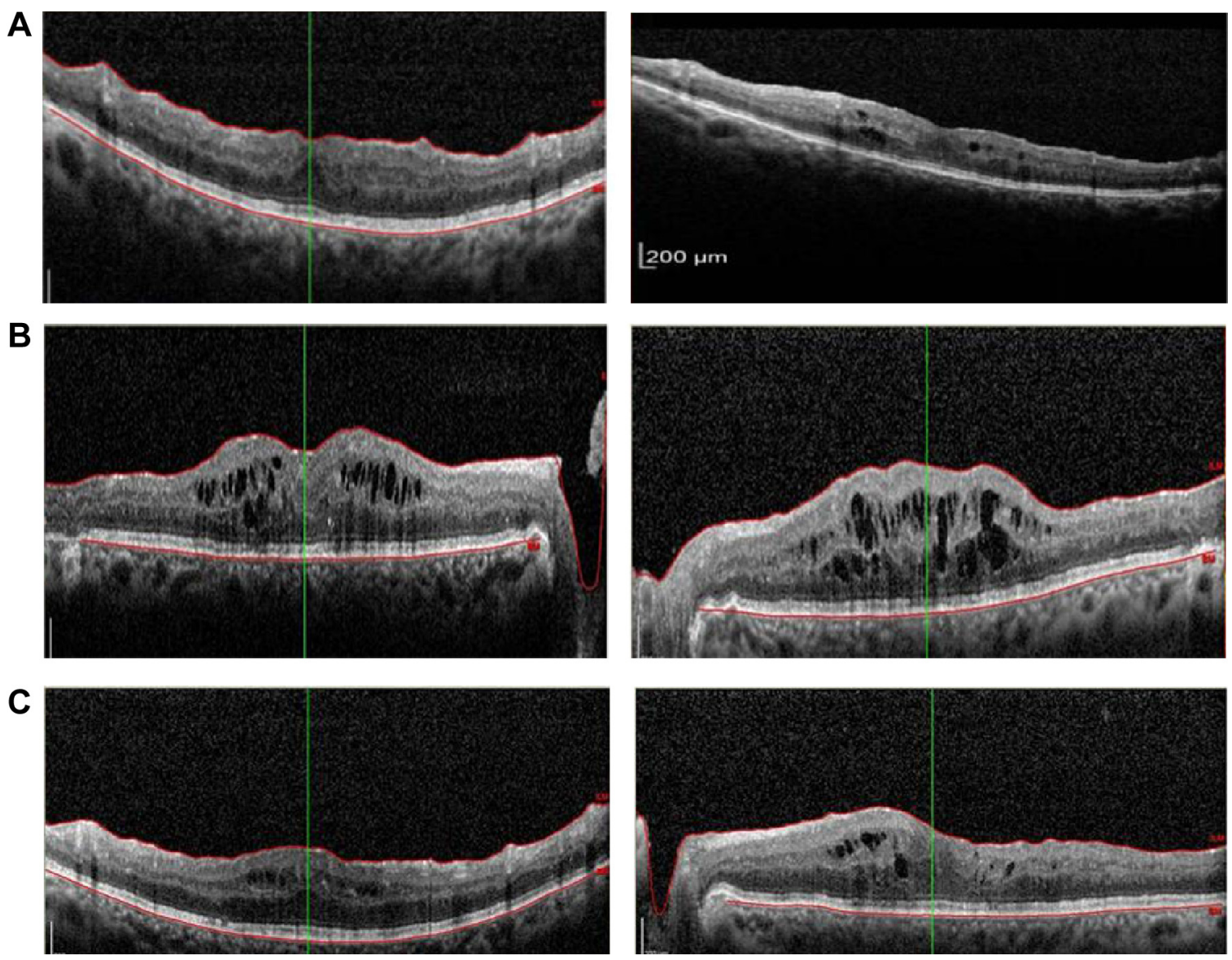

Figure 3 (A) Optical coherence tomography images of both maculae showing marked reduction in the intracellular and subretinal fluid 8 weeks after systemic treatment for diabetic nephropathy. (B) Optical coherence tomography images of both maculae showing recurrent macular edema with the discontinuation of the diuretic and angiotensinconverting enzyme inhibitor medication. (C) Optical coherence tomography images of both maculae I month after resuming the diuretic and angiotensin-converting enzyme inhibitor, showing improvement only in the macular edema.

eye and 20/50 in the left eye, with a marked increase in central thickness and in cystoid macular edema (Figure 3B).

The systemic medications were all resumed a month later, with regression of the macular edema and an increase in VA to $20 / 25$ in both eyes (Figure 3C).

\section{Discussion}

Kimmelstiel-Wilson syndrome was discovered by two physicians, Clifford Wilson and Paul Kimmelstiel in $1936 .^{2}$ It is a progressive nephropathy secondary to glomerular disease that usually manifests 15-25 years after the diagnosis of type 2 diabetes and within 5 years for type 1 diabetics. ${ }^{3,4}$ Kimmelstiel-Wilson syndrome affects 25\%-35\% of patients under 30 years of age. ${ }^{2,3}$ The disease is more frequent in men, and it may cause premature death in young diabetics 2 or 3 years after the appearance of the initial lesions. ${ }^{2,3}$ The rate of progression may increase in patients with poorly controlled blood pressure and high cholesterol. ${ }^{3,4}$

Damage to the glomeruli causes blood and protein, mainly albumin, loss through the urine. Low albumin in the blood with a secondary decrease in plasma oncotic pressure causes fluid to leak out of the bloodstream, resulting in edema and swelling of soft tissues such as the face, ankles, eyes, feet, and abdomen. Coexisting high blood pressure will aggravate the problem by increasing luminal hydrostatic pressure. ${ }^{2}$

Schwartz et $\mathrm{al}^{4}$ suggest that there is a distinct correlation of retinal and glomerular pathologies in the pathophysiological processes in Kimmelstiel-Wilson syndrome. Diabetic nephropathy with secondary albuminuria is one possible pathogenetic mechanism for DME. Parving et $\mathrm{al}^{5}$ state that the presence of diabetic retinopathy strongly suggests that a diabetic glomerulopathy is the cause of albuminuria. From these observations, we believe that proteinuria and the presence of persistent DME may confirm the diagnosis of diabetic nephropathy without requiring a renal biopsy.

Refractory DME can be another warning sign and feature of glomerulosclerosis in diabetic patients. These patients can be evaluated by the internist to rule out the possibility of associated diabetic nephropathy as a cause of their persistent and refractory DME. Early diagnosis can be achieved by a 
simple dipstick test to diagnose proteinuria, the primary sign of damaged glomeruli that cause blood and protein loss via the urine.

\section{Conclusion}

This case report clearly demonstrates the role of diabetic glomerulosclerosis in the diagnosis of persistent and refractory macular edema. Early recognition of this pathology by timely medical referral in suspicious cases of refractory DME may save the patient from this progressive and lethal disease and delay progression to renal failure. Additionally it may save the patient unnecessary local ocular intervention.

This case indicates that there are other systemic abnormalities which may play a significant role in poorly controlled diabetic maculopathy, and systemic rather than local intervention may be warranted.

\section{Disclosure}

The author declares no conflicts of interest in this work.

\section{References}

1. Nguyen QD, Shah SM, Khwaja AA, et al; READ-2 Study Group. Twoyear outcomes of the ranibizumab for edema of the mAcula in diabetes (READ-2) study. Ophthalmology. 2010;117(11):2146-2151.

2. Kimmelstiel P, Wilson C. Benign and Malignant Hypertension and Nephrosclerosis: A Clinical and Pathological Study. Am J Pathol. 1936; 12(1):45-82.3.

3. Zelmanovitz T, Gerchman F, Balthazar AP, Thomazelli FC, Matos JD, Canani LH. Diabetic nephropathy. Diabetol Metab Syndr. 2009; 1(1): 10 .

4. Schwartz MM, Lewis EJ, Leonard-Martin T, Lewis JB, Batlle D. Renal pathology patterns in type II diabetes mellitus: relationship wwith retinopathy. The Collaborative Study Group. Nephrol Dial Transplant. 1998;13(10):2547-2552.

5. Parving HH, Gall MA, Skøtt P, et al. Prevalence and causes of albuminuria in non-insulin-dependent diabetic patients. Kidney Int. 1992; 41(4):758-762.
Clinical Ophthalmology

\section{Publish your work in this journal}

Clinical Ophthalmology is an international, peer-reviewed journal covering all subspecialties within ophthalmology. Key topics include: Optometry; Visual science; Pharmacology and drug therapy in eye diseases; Basic Sciences; Primary and Secondary eye care; Patien Safety and Quality of Care Improvements. This journal is indexed on

Submit your manuscript here: http://www.dovepress.com/clinical-ophthalmology-journal

\section{Dovepress}

PubMed Central and CAS, and is the official journal of The Society of Clinical Ophthalmology (SCO). The manuscript management system is completely online and includes a very quick and fair peer-review system, which is all easy to use. Visit http://www.dovepress.com/ testimonials.php to read real quotes from published authors. 